\title{
REMOÇÃO DE ÍONS CÁDMIO DE EFLUENTES LÍQUIDOS ATRAVÉS DE TÉCNICAS ELETROQUÍMICAS UTILIZANDO TELAS DE AÇO-CARBONO COMO CATODO
}

\author{
Lisiane Heinen Fernandes ${ }^{l}$ \\ Fernando Benedicto Mainier \\ Luciane Pimentel Costa Monteiro ${ }^{3}$
}

\begin{abstract}
Resumo: Atualmente muito se tem discutido sobre a poluição das águas por metais pesados. Efluentes industriais contendo esses metais podem se tornar um grande problema ao meio ambiente, principalmente, quando não tratados adequadamente. Entre esses metais pesados está o cádmio, elemento extremamente tóxico, bioacumulativo, causador de vários males aos homens e que ocupa atualmente o sétimo lugar nas substâncias tóxicas com maior risco de causar danos aos seres humanos. Este trabalho tem por objetivo demonstrar algumas características deste elemento e sugerir um simples e eficiente tratamento para remoção de íons cádmio de águas residuárias. Como resultado dos experimentos, conseguiu-se uma remoção de aproximadamente $98 \%$ dos íons cádmio dos efluentes estudados e, também, foram levantados os fatores que afetaram o processo de remoção.
\end{abstract}

Palavras-chave: cádmio, remoção de metais pesados, contaminações industriais.

\begin{abstract}
Actually, much has been discussed about water pollution by heavy metals. Industrial effluents containing this type of metal can become a serious problem to the environment, specially, when not properly treated. Among these heavy metals there is the cadmium, a highly toxic element, bioaccumulative, the cause of many diseases in human. Actually, is the seventh place among the toxic substances with the major risk of causing damage to human. This paper aims to show some characteristics of this element and suggest a simple and effective treatment for the removal of cadmium ions from simulated wastewater. As a result of the experiments, it was gotten a removal of $98 \%$ of cadmium ions from studied effluents and also the factors that affected the removal process.
\end{abstract}

Keywords: cadmium, heavy metals removal, industrial contaminations.

${ }^{1}$ Pós graduação Engenharia Civil - UFF lisianehf@yahoo.com.br

${ }^{2}$ Departamento de Engenhara Química e Petróleo - UFF fmainier@uol.com.br

${ }_{3}^{3}$ Departamentode Engenharia Química e Petróleo - UFF lucianemonteiro@predialnet.com.br 


\section{INTRODUÇÃO}

Nas últimas quatro décadas, questôes ligadas ao meio ambiente ganharam destaque em âmbito mundial. Problemas como emissóes de gases, poluição das águas e descarte de resíduos passaram a ser amplamente discutidos e estudados, buscando-se sempre por soluções que visem o menor dano possível ao planeta.

Mas, mesmo com toda essa preocupação conseguida, o meio ambiente ainda sofre com o descaso de algumas empresas com relação a seus resíduos, com a falta de saneamento em algumas cidades e o acúmulo de lixo em lugares impróprios.

Estudos como o de Jimenez et $\mathrm{al}^{1}$, nos mostram números alarmantes sobre a produção de resíduos perigosos por indústrias no Brasil - na ordem de três milhões de toneladas/ano - e apontam uma realidade ainda pior, destes resíduos produzidos, somente 850 mil toneladas recebem tratamento adequado, os $72 \%$ restantes são depositados indevidamente em lixôes ou descartados em cursos d'água sem qualquer tipo de tratamento.

Dentre os resíduos industriais perigosos pode-se encontrar elementos altamente poluentes como o metal pesado cádmio. Este se destaca pela elevada toxicidade, a grande capacidade de acumulação nos tecidos, podendo sua meia vida chegar a quarenta anos ${ }^{2 ; 3}$ e também por ser considerado causador de vários males a saúde humana, incluindo a doença de Itai-itai.

Segundo pesquisas realizadas em 2005 pelas Agências Americanas ATSDR (Agency for Toxic Substances and Disease Registry) e EPA (Environmental Protection Agency) o cádmio ocupa o sétimo lugar nas substâncias tóxicas com maior risco de causar danos ao homem.

De acordo com o IARC ${ }^{4}$, Agência Internacional para Pesquisa do Câncer, este elemento é classificado como cancerígeno para o ser humano (grupo I). Alguns trabalhos relacionam os tipos de câncer que podem estar associados com a exposição ao cádmio, são eles: câncer nos rins e trato urinário ${ }^{5}$, fígado e estômago ${ }^{6}$ e câncer de próstata ${ }^{7}$.

Outros problemas ligados ao cádmio são: efeitos tóxicos nos rins, pulmóes e sistema reprodutor $^{8}$. Seu acúmulo no organismo pode também ser responsável pelo desenvolvimento de hipertensão, doenças do coração, enfisema, formação de catarata nos olhos, atrofia muscular e porosidade nos ossos ${ }^{9 ; 10}$.
Efeitos neuropsicológicos também foram atribuídos à exposição ao cádmio, como alterações na memória, alterações cognitivas, velocidade psicomotora entre outras ${ }^{11}$.

Em locais com severas contaminações por cádmio, há um aumento de doenças nos ossos nos seres humanos. Estudos recentes têm mostrado que quanto maior o nível de cádmio no sangue menor a densidade óssea da pessoa ${ }^{12}$.

Vários efeitos da toxicidade do cádmio são notados em plantas: a) problemas na germinação - quando sementes são postas para germinar em ambientes com altos índices de cádmio, a respiração, crescimento do eixo embrionário e da radícula são comprometidos ${ }^{13}$; b) clorose foliar; c) alterações na absorção, transporte e uso de macroelementos como cálcio, fósforo, potássio e enxofre ${ }^{14}$; d) diminuição da taxa de fotossíntese; e) mudanças nas atividades enzimáticas ${ }^{15}$; f) murchamento de folhas ${ }^{16} ; \mathrm{g}$ ) inibição do crescimento das plantas ${ }^{16}$.

Contudo, mesmo com essa alta toxicidade, o cádmio ainda é muito utilizado na indústria, estando presente no setor de baterias, recobrimentos, pigmentos e estabilizadores. Estudos sobre os rejeitos industriais contendo cádmio mostram que cerca de 30 mil toneladas do elemento são lançadas por ano no meio ambiente ${ }^{17}$.

Assim, visando à preservação do meio ambiente, buscando principalmente à diminuição e/ ou eliminação dos íons cádmio dos resíduos industriais, utilizou-se das teorias eletroquímicas para desenvolver um método simples, eficiente e barato para a remoção deste elemento de efluentes líquidos.

Deste modo, este trabalho tem por objetivo avaliar a capacidade de remoção de íons cádmio utilizando telas de aço-carbono como catodo, uma vez que esse material é de baixo custo quando comparado aos materiais normalmente utilizados para este fim. Após isso, serão analisadas mudanças no processo - como tempo e corrente - e também no catodo - como área e geometria - buscando por melhores eficiências de remoção dos íons.

\section{PARTE EXPERIMENTAL}

O estudo da remoção dos íons cádmio iniciou-se pela preparação de soluções simulando efluentes. Após essa etapa, passou-se para a con- 
fecção e limpeza das placas utilizadas como catodo e anodo. Por último descreve-se a montagem e as condiçõos de operação da célula eletroquímica. Todas as etapas do experimento são apresentadas detalhadamente a seguir.

\subsection{PREPARAÇÃO DAS SOLUÇÕES}

Foram preparadas soluções com o objetivo de simular efluentes com três diferentes concentraçôes de íons cádmio, foram elas: $500 \mathrm{mg}$ de $\mathrm{Cd}^{+2} / \mathrm{L}, 250 \mathrm{mg} \mathrm{de} \mathrm{Cd}^{+2} / \mathrm{L}$ e $50 \mathrm{mg} \mathrm{de} \mathrm{Cd}^{+2} / \mathrm{L}$. Todas preparadas a partir de cloreto de cádmio monohidratado $\left(\mathrm{CdCl}_{2} \cdot \mathrm{H}_{2} 0\right)$.

\subsection{PREPARAÇÃO DOS CATODOS}

Neste estudo, placas de aço-carbono foram utilizadas como catodo. Essas placas foram escolhidas devido ao baixo custo, fácil manuseio e grande disponibilidade no mercado. Assim, foram adquiridas duas telas com diferentes tamanhos de fio, uma com diâmetro de $0,1 \mathrm{~mm}$ e outra com $0,15 \mathrm{~mm}$, de aproximadamente $1 \mathrm{~m}^{2}$, que foram cortadas em diferentes tamanhos. Todas as placas passaram por um processo de limpeza química visando à remoção de graxas, óxidos ou outros resíduos que pudessem interferir ou diminuir a eficiência de remoção do cádmio.

\subsection{MONTAGEM DOS CATODOS}

A fim de verificar uma possível diferença no valor das eficiências de remoção de íons cádmio, foram confeccionados modelos diferentes de catodos, como descrito a seguir:

\section{MODELO 1:}

O primeiro modelo de catodo foi confeccionado a partir de dois cortes da tela com maior diâmetro de fio $(0,15 \mathrm{~mm})$ com tamanhos de 7 x $5 \mathrm{~cm}$, unidos por grampos e separados por um afastador de madeira de $4 \mathrm{~mm}$. Dois centímetros da placa não entram em contato com a solução, essa área foi reservada para prender os fios que ligam a fonte.

O cálculo da área metálica em contato com a solução é dado pela equação 1 a seguir:

$$
\text { Área }_{\text {real }}=n^{\circ}{ }^{\circ} \text { iosx } A_{\text {fio }}=n^{\circ} \text { fiosøxdxl (equação 1) }
$$

Onde: d é o diâmetro do fio e l é o comprimento do fio.

Como cada tela possui 58 fios com diâmetro de $0,15 \mathrm{~mm}$ e que o comprimento do fio em contato com a solução é de $5 \mathrm{~cm}$, a área real do modelo é de $27,33 \mathrm{~cm}^{2}$.

\section{MODELO 2:}

O segundo modelo de catodo foi realizando a partir de dois cortes da tela de menor diâmetro, com tamanho de $7 \times 5 \mathrm{~cm}$, afastadas por um pedaço de madeira de $4 \mathrm{~mm}$. O número de fios em cada tela é de 116, sendo que o diâmetro do fio é de $0,1 \mathrm{~mm}$.

Utilizando-se a equação 1 , foi obtido o valor de $36,44 \mathrm{~cm}^{2}$ de área metálica do modelo.

\section{MODELO 3:}

O terceiro modelo de catodo foi realizado utilizando-se um corte da tela com diâmetro maior, com tamanho de $10 \times 5 \mathrm{~cm}$ em contato com a solução. A placa possui 27 fios com $10 \mathrm{~cm}$ de comprimento e 62 fios de $5 \mathrm{~cm}$. O cálculo realizado para obtenção da área metálica da placa é mostrado na equação 2. Este modelo foi empregado em espiral.

Área $_{\text {real }}=[(10 \varpi x 0,015) \times 27]+$

$[(5 \mathrm{x} \varpi \times 0,015) \times 62]=36,44 \mathrm{~cm}^{2} \quad$ (equação 2$)$

\section{MODELO 4:}

Este modelo de catodo foi realizado utilizando-se um corte da tela com diâmetro menor, com tamanho de $10 \times 5 \mathrm{~cm}$. Este foi o tamanho utilizado para ter contato com a solução. A placa possui 60 fios com $10 \mathrm{~cm}$ de comprimento e 112 fios de $5 \mathrm{~cm}$. O cálculo realizado para obtenção da área metálica da placa é demonstrado na equação 3. Este modelo foi empregado em espiral.

Área ${ }_{\text {real }}=[(10 \varpi \times 0,010) \times 60]+$ $+[(5 \times \bar{x} \varpi \times 0,01) \times 112]=36,44 \mathrm{~cm}^{2} \quad$ (equação 3$)$

\subsection{PREPARAÇÃO DO ANODO}

Como anodo utilizou-se uma placa plana de platina de $7 \mathrm{~cm}^{2}$. Assim como as placas usadas como catodo, esta passou por limpeza química para remoção de possíveis interferentes. 


\subsection{MONTAGEM DA CÉLULA ELETROLÍTICA}

A célula eletrolítica montada para este estudo é formada de uma placa de platina como anodo (mostrada na figura 1 ao lado direito) e um catodo - neste, foram utilizados os modelos descritos anteriormente.

Agitação foi empregada neste processo e, para isso, utilizou-se um agitador magnético da marca Quimis. Para a aplicação da tensão na célula, fez-se o uso de uma fonte de alimentação, de corrente contínua, da marca Mimipa, modelo 303D. O processo foi realizado a temperatura e pressão ambiente.

Foi necessário o uso um suporte para prender os fios vindos da fonte de alimentação e também para dar maior sustentação aos eletrodos.

O recipiente onde ocorreu o processo eletroquímico possui volume de $280 \mathrm{~mL}$, sendo que o volume empregado de solução foi de $250 \mathrm{~mL}$.

$\mathrm{O}$ esquema da célula é apresentado na figura 1 .

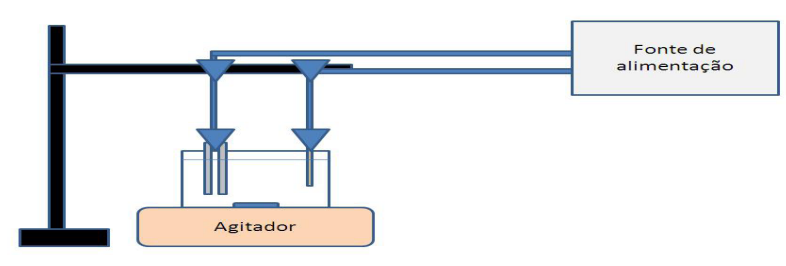

Figura 1. Esquema da montagem do processo de remoção

\section{RESULTADOS E DISCUSSÃO}

Uma das preocupações iniciais deste trabalho foi a escolha de uma técnica de remoção de íons que causasse o menor impacto possível ao meio ambiente. Normalmente os tratamentos mais utilizados para a retirada dos íons cádmio de efluentes são: precipitação, separação por membranas $^{20}$ e biossorção ${ }^{18,21}$, todos formando ao final do processo um novo rejeito com altas concentrações do metal removido do efluente, necessitando assim de local adequado para seu descarte.

Buscando-se por soluções para a não geração de resíduos, assim como, recuperação e possível utilização do metal retirado, escolheu-se o processo de remoção eletroquímico ${ }^{19}$. Este método não requer emprego de reagentes tóxicos, não produz lamas, dá a possibilidade de reutilização do metal depositado, e, hoje pode ser considerada uma tecnologia limpa, já que o elétron quando vindo de uma fonte renovável de energia é considerado um reagente limpo.

Estabelecendo-se o tipo de tratamento, fixaram-se algumas condições de operação do experimento a fim de avaliar a capacidade de remoção das placas de aço-carbono. Primeiramente definiu-se a tensão de operação em $20 \mathrm{~V}$, significando isso uma corrente de $0,08 \mathrm{~A}$ para a solução de $500 \mathrm{mg}$ de $\mathrm{Cd}^{+2} / \mathrm{L}$, de $0,06 \mathrm{~A}$ para a de $250 \mathrm{mg}$ de $\mathrm{Cd}^{+2} / \mathrm{L}$ e de $0,04 \mathrm{~A}$ para a de $50 \mathrm{mg} \mathrm{de} \mathrm{Cd}^{+2} / \mathrm{L}$. O tempo de operação foi de 90 minutos e os modelos de catodo utilizados foram os modelos 1 e 2 .

Cabe salientar que todos os resultados mostrados neste trabalho são dados por médias aritméticas de experimentos realizados em duplicatas.

Todos os valores de concentrações das soluções, tanto anteriores como posteriores ao processo de remoção, foram obtidos através de análises feitas em um analisador voltamétrico - V.A. 797 - da marca Computrace. A seguir são mostrados os resultados obtidos.

Tabela 1. Remoção de íons cádmio utilizando tensão de $20 \mathrm{~V}$ e tempo de 90 minutos

\begin{tabular}{|c|c|c|c|}
\hline Modelo de catodo & $\begin{array}{c}\text { Efluente concentração } \\
\text { inicial }\end{array}$ & $\begin{array}{c}\text { Efluente Concentração } \\
\text { pós-remoção }\end{array}$ & $\begin{array}{c}\text { Eficiência de } \\
\text { remoção }\end{array}$ \\
\hline Modelo 1 & $516,990 \mathrm{mg} \mathrm{de} \mathrm{Cd}+2 / \mathrm{L}$ & $180,150 \mathrm{mg} \mathrm{de} \mathrm{Cd}+2 / \mathrm{L}$ & $65,2 \%$ \\
\hline Modelo 2 & $516,990 \mathrm{mg} \mathrm{de} \mathrm{Cd}+2 / \mathrm{L}$ & $159,830 \mathrm{mg} \mathrm{de} \mathrm{Cd}+2 / \mathrm{L}$ & $69,1 \%$ \\
\hline Modelo1 & $257,160 \mathrm{mg} \mathrm{de} \mathrm{Cd}+2 / \mathrm{L}$ & $65,270 \mathrm{mg} \mathrm{de} \mathrm{Cd}^{+2} / \mathrm{L}$ & $74,6 \%$ \\
\hline Modelo 2 & $257,160 \mathrm{mg} \mathrm{de} \mathrm{Cd}^{+2} / \mathrm{L}$ & $42,710 \mathrm{mg} \mathrm{de} \mathrm{Cd}^{+2} / \mathrm{L}$ & $83,4 \%$ \\
\hline Modelo 1 & $46,210 \mathrm{mg} \mathrm{de} \mathrm{Cd}^{+2} / \mathrm{L}$ & $21,871 \mathrm{mg} \mathrm{de} \mathrm{Cd}^{+2} / \mathrm{L}$ & $52,7 \%$ \\
\hline Modelo 2 & $46,210 \mathrm{mg} \mathrm{de} \mathrm{Cd}^{+2} / \mathrm{L}$ & $15,570 \mathrm{mg} \mathrm{de} \mathrm{Cd}^{+2} / \mathrm{L}$ & $66,3 \%$ \\
\hline
\end{tabular}


Como pode ser visto o catodo de aço-carbono é capaz de remover os íons de cádmio das soluções.

Para analisar como ocorre a separação dos íons, são mostradas as reaçóes envolvidas no processo de remoção, e, na figura 2 é ilustrado o funcionamento da célula.

- Anodo:

$\mathrm{H}_{2} \mathrm{O} \rightarrow \frac{1}{2} \mathrm{O}_{2}+2 \mathrm{H}^{+}+2 e \quad$ (reação 1$)$

- Catodo: $C d^{2+}+2 e \rightarrow C d \quad$ (reação 2)

Além das reações principais, reações secundárias podem ocorrer:

- Anodo: $2 \mathrm{Cl}^{-} \rightarrow \mathrm{Cl}_{2}+2 e \quad$ (reação 3)

- Catodo:

$2 \mathrm{H}_{2} \mathrm{O}+2 e \rightarrow \mathrm{H}_{2}+2 \mathrm{OH}^{-} \quad($ reação 4$)$

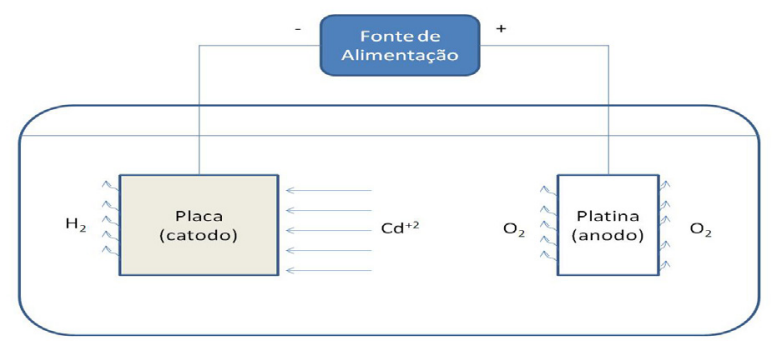

Figura 2. Esquema da célula eletrolítica

Analisando os dois modelos de placas utilizados, pode-se perceber que o modelo 2 apresenta uma eficiência de remoção superior ao modelo 1 em todas as análises. A partir desses resultados percebe-se que existe influência do diâmetro do fio sobre a eficiência de remoção. Esta influência pode ser justificada pela maior área de exposição dos íons cádmio à placa metálica.

Tendo sido constatada a capacidade de remoção de íons com a utilização do catodo de aço-carbono, recorreu-se a teorias eletroquímicas em busca de eficiências maiores para o sistema. Assim, fundamentos da Lei de Faraday foram aplicados para este caso, onde $\mathrm{F}$ é a constante de Faraday $(96485 \mathrm{C} / \mathrm{mol}) .{ }^{19}$

A quantidade de substância depositada é diretamente proporcional a quantidade de eletricidade que passou através da solução. As quantidades das diferentes substâncias que se depositam são proporcionais aos seus equivalentes eletroquímicos.

Conforme esse enunciado, pode-se representá-lo pela equação 4, abaixo:

EQUAÇÃO 4: $\quad$ Massa $=\frac{E . I . t}{F}$

Onde, E- é o equivalente eletroquímico (massa atômica/carga), I é a corrente e t, é o tempo.Utilizando-se a equação da Lei de Faraday para o sistema de remoção e, estabelecendo-se a remoção total da massa de cádmio presente em solução e tendo pré-definida uma corrente/tensão utilizada nos experimentos, foi possível calcular um tempo teórico para esse processo. Assim, para a solução de $500 \mathrm{mg} \mathrm{Cd}^{+2} / \mathrm{L}$ e utilizando-se uma corrente de $0,15 \mathrm{~A}$ o tempo teórico deste processo foi de aproximadamente 95 minutos. Já para a solução de $250 \mathrm{mg} \mathrm{Cd}^{+2} / \mathrm{L}$ e, utilizando-se uma corrente de 0,09A, o tempo teórico deste processo foi de aproximadamente 80 minutos.

Contudo, os tempos teóricos fornecidos pela Lei de Faraday só são conseguidos em processos onde há $100 \%$ de eficiência de corrente, isto é, nos processos onde toda corrente aplicada é utilizada na deposição do material de interesse, o que não acontece normalmente. Muitas vezes a corrente é utilizada na deposição de algum contaminante ou ainda em reações secundárias, como a liberação de hidrogênio no catodo, conforme observado na reação 4 . A Figura 3 ilustra a liberação de hidrogênio durante os experimentos.

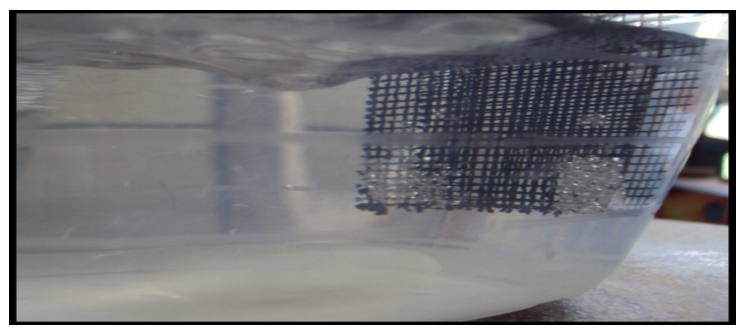

Figura 3. Desprendimento de hidrogênio no catodo

Atualmente muito se tem discutido sobre a poluição das águas por metais pesados. Efluentes industriais contendo esses metais podem se tornar um grande problema ao meio ambiente, principalmente, quando não tratados adequadamente. Como resultado dos experimentos em célula eletrolítica para remoção de íons cádmio, conseguiu-se uma eficiência de remoção de aproximadamente 98\%, demonstrando a viabilidade do uso desta técnica. 
Tabela 2. Comparação de resultados da remoção utilizando somente o modelo 2 de catodo e tensão de $30 \mathrm{~V}$ para diferentes tempos

\begin{tabular}{|c|c|c|c|}
\hline Tempo & $\begin{array}{c}\text { Efluente concentração } \\
\text { inicial }\end{array}$ & $\begin{array}{c}\text { Efluente Concentração } \\
\text { pós-remoção }\end{array}$ & $\begin{array}{l}\text { Eficiência de } \\
\text { remoção }\end{array}$ \\
\hline 95 minutos & $498,572 \mathrm{mg}$ de $\mathrm{Cd}^{+2} / \mathrm{L}$ & $16,520 \mathrm{mg} \mathrm{de} \mathrm{Cd}^{+2} / \mathrm{L}$ & $96,7 \%$ \\
\hline 120 minutos & $498,572 \mathrm{mg} \mathrm{de} \mathrm{Cd}^{+2} / \mathrm{L}$ & $10,030 \mathrm{mg} \mathrm{de} \mathrm{Cd}^{+2} / \mathrm{L}$ & $98,0 \%$ \\
\hline 80 minutos & $239,710 \mathrm{mg} \mathrm{de} \mathrm{Cd}^{+2} / \mathrm{L}$ & $71,106 \mathrm{mg} \mathrm{de} \mathrm{Cd}^{+2} / \mathrm{L}$ & $71,1 \%$ \\
\hline 120 minutos & $239,710 \mathrm{mg} \mathrm{de} \mathrm{Cd}^{+2} / \mathrm{L}$ & $79,913 \mathrm{mg} \mathrm{de} \mathrm{Cd}^{+2} / \mathrm{L}$ & $79,9 \%$ \\
\hline
\end{tabular}

Como pode ser notado, utilizando tempos superiores aos teóricos é possível uma remoção mais eficiente dos íons cádmio das soluçôes, comprovando que existe perda da eficiência de corrente. Vale salientar que foram utilizados como catodo apenas o modelo 2, já que este mostrou-se mais eficiente.

Como mostrado na Tabela 2, utilizando o modelo 2 do catodo e um tempo de 120 minutos, valores satisfatórios de eficiência de remoção são conseguidos para este processo.
Dando continuidade ao trabalho, tendo por objetivo analisar se a geometria da placa alteraria a eficiência de remoção, foram confeccionadas placas com formato em espiral, e estas foram comparadas com placas planas.

Diferente do modelo das placas planas, que eram formadas por duas peças, a placa em espiral foi feita de forma contínua, possuindo tamanho duas vezes maior que cada peça utilizada no modelo linear.

Tabela 3. Influência da geometria na eficiência de remoção

\begin{tabular}{|c|c|c|c|}
\hline Geometria & $\begin{array}{c}\text { Efluente concentração } \\
\text { inicial }\end{array}$ & $\begin{array}{c}\text { Efluente Concentração } \\
\text { pós-remoção }\end{array}$ & $\begin{array}{c}\text { Eficiência de } \\
\text { remoção }\end{array}$ \\
\hline $\begin{array}{c}\text { Placa plana }- \\
\text { Modelo 2 }\end{array}$ & $257,160 \mathrm{mg} \mathrm{de} \mathrm{Cd}+2 / \mathrm{L}$ & $42,710 \mathrm{mg} \mathrm{de} \mathrm{Cd}^{+2} / \mathrm{L}$ & $83,4 \%$ \\
\hline $\begin{array}{c}\text { Placa em espiral }- \\
\text { Modelo 4 }\end{array}$ & $257,160 \mathrm{mg} \mathrm{de} \mathrm{Cd}+2 / \mathrm{L}$ & $45,000 \mathrm{mg} \mathrm{de} \mathrm{Cd} \mathrm{d}^{+2} / \mathrm{L}$ & $82,5 \%$ \\
\hline $\begin{array}{c}\text { Placa plana }- \\
\text { Modelo 1 }\end{array}$ & $46,210 \mathrm{mg} \mathrm{de} \mathrm{Cd}+2 / \mathrm{L}$ & $21,870 \mathrm{mg} \mathrm{de} \mathrm{Cd}^{+2} / \mathrm{L}$ & $52,7 \%$ \\
\hline $\begin{array}{c}\text { Placa em espiral }- \\
\text { Modelo 3 }\end{array}$ & $46,210 \mathrm{mg} \mathrm{de} \mathrm{Cd}^{+2} / \mathrm{L}$ & $20,730 \mathrm{mg} \mathrm{de} \mathrm{Cd}^{+2} / \mathrm{L}$ & $55,1 \%$ \\
\hline
\end{tabular}

Como pode ser visto, foram comparados modelos com mesma área real, já que anteriormente foi mostrado que a área pode influenciar na eficiência do processo.

Nas comparações realizadas, pode-se perceber que os valores das eficiências de remoção são muito semelhantes, na primeira comparação (modelo 2 e 4) cada modelo com área de $36,44 \mathrm{~cm}^{2}$, tem-se uma diferença de eficiência mínima, já na comparação entre o modelo 1 e 3 - com área de $24,33 \mathrm{~cm}^{2}$ a diferença entre as eficiências é um pouco mais significante.

Mesmo assim, como as diferenças de valores da eficiência de remoção são muito pequenos, entre 1 e 2 pontos percentuais, não se pode concluir que a geometria causou algum tipo de melhoria na eficiência deste processo. 
Pode-se especular ainda, que não houve diferença na eficiência de remoção neste processo devido ao tipo de fluxo mássico na célula. Provavelmente se fosse utilizado um fluxo perpendicular ao catodo em espiral a remoção de íons de cádmio seria maior.

\section{CONCLUSÓES}

Após a realização dos experimentos pode-se concluir que o processo eletroquímico é um método simples e eficaz na remoção dos íons cádmio de efluentes e que a célula eletrolítica utilizada nos experimentos foi capaz de promover a remoção dos íons cádmio dos efluentes simulados.

O catodo de aço-carbono mostrou-se uma opção barata, simples e eficiente para ser utilizado na célula eletrolítica.

Das três diferentes concentrações de soluções utilizadas nos experimentos, a solução de 500 $\mathrm{mg} \mathrm{de} \mathrm{Cd}^{+2} / \mathrm{L}$ apresentou os melhores resultados de remoção dos íons cádmio. Sendo que a maior eficiência de remoção foi alcançada utilizando-se a corrente de $0,15 \mathrm{~A}$, tensão de $30 \mathrm{~V}$, tempo de remoção de 120 minutos e catodo modelo 2. Para estas condiçôes a remoção foi de $98 \%$.

$\mathrm{O}$ estudo dos diferentes diâmetros de tela e conseqüentemente diferentes áreas, concluiu que independente da concentração de íons do efluente, quanto maior a área metálica em contato com a solução, maior será a eficiência de remoção de íons de cádmio do processo.

Sobre a influência da geometria do catodo e a eficiência de remoção, quando comparadas placas planas e em espirais, nenhuma alteração na eficiência foi notada.

\section{REFERÊNCIAS}

1. JIMENEZ, R. S.; BOSCO, S. M. D.; CARVALHO, W. A. "Remoção de metais pesados de efluentes aquosos pela zeólita natural escolecita influência da temperatura e do $\mathrm{pH}$ na adsorção em sistemas monoelementares". Química Nova, v. 27, n.1, 2004.

2. OGA, S. "Fundamentos de toxicologia". São Paulo: Atheneu, 1996.

3. WHO. World Health Organization. "Evaluation of Mercury, Lead, Cadmium and the Food
Additives Amaranth, Diethylpyrocarbonate, and Octyl Gallate”. Geneva, 1972.

4. IARC. INTERNACIONAL AGENCY FOR RESEARCH ON CANCER. "Beryllium, cadmium, mercury and exposures in the glass manufacturing industry". IARC Monographs on the Evaluation of Carcinogenic Risk of Chemicals to Humans, v. 58 p. 444, 1993.

5. MOTA, S. Introdução à Engenharia Ambiental. 3. ed. Rio de Janeiro:Associação Brasileira de Engenharia Sanitária e Ambiental, 2003. v.1. 416 p.

6. SHIGEMATSU I.; MINOWA M.; YOSHIDA T. "Recent results of health examinations on the general population in cadmium-polluted and control areas in Japan." Environ Health Perspect, v. 28 , p. 205-210, 1979.

7. BAKO G.; SMITH E. S.; HANSON J.; DEWAR R. "The geographical distribution of hight cadmium concentrations in the environment and prostate cancer in Alberta." Can J Public Health, v. 73, p. 92-94, 1982.

8. SOUZA, S. N.; SILVA, M. S.; LENZI, E.; LUCHESE, E. B. "Avaliação de parâmetros referentes ao cádmio como contaminante do lodo de esgoto aplicado num Latossolo Vermelho Escuro". Seminário sobre gerenciamento de biossólidos do mercosul. Curitiba, 1998.

9. HALLENBECK, W. H. "Human health effects of exposure to cadmium". J Cell Mol Life Sci, v. 40, n. 2, p. 136-142, 1984.

10. RAMAKRISHNAN S. et al. "Smoking of beedies and cataract: cadmium and vitamin $C$ in the lens and blood." Br J Ophthalmol, v. 79, p. 202-206, 1995.

11. CARY, R.; CLARKE S.; DELIC J. "Effects of combined exposure to noise and toxic substances - Critical review of the literature". Ann Occup Hyg, v. 41, p. 455-465, 1997.

12. OISSON, I. M. et al. "Cadmium in Food Production Systems: A Health Risk for Sensitive Population Groups". AMBIO: A Journal of the Human Environment. p. 344-351, 2005. 
13. KABATA-PENDIAS, A.; PENDIAS, $\mathrm{H}$. "Trace elements in soils and plants". 3 ed. CRC Press, London, p.123-127, 2000.

14. JIANG, R. F; MA, D. Y.; ZHAO. F. J.; McGRATH, S. P. "Cadmium hyperaccumulation protects Thlaspi caerulescens from leaf feeding damage by thrips". New Phytologist, v. 167, p. 805-814, 2005.

15. GUIMARÃES, M. A.; SANTANA, T. A.; SILVA, E. V.; ZENZEN, I. L.; LOUREIRO, M. E. "Toxicidade e tolerância ao cádmio em plantas". Revista Trópica - Ciências Agrárias e Biológicas, v. 2, p. 58-68, 2008.

16. SOARES, C. R. F. S. et al. "Fitotoxidez de cádmio para Eucalyptus maculata E E. urophylla EM solução nutritiva”. Sociedade de Investigações Florestais, v. 29, n.2, p.175-183, Viçosa, 2005.

17. AZEVEDO, B. S. M.; RIZZO, A. C. L.; FERREIRA L. S. G.; SOBRAL, L. G. S. REICHWALD, D.; WALCHAN, G. M. "Utilização da fibra da casca de coco verde como suporte para a formação de biofilme visando o tratamento de efluentes". Série Tecnologia Ambiental. 140 p. CETEM/MCT, Rio de Janeiro, 2008.
18. HUAMÁN PINO, G. A. Biossorção de Metais Pesados Utilizando Pó da Casca de Coco Verde (Cocos nucífera).113p. Dissertação de Mestrado - Departamento de Ciência dos Materiais e Metalurgia, Pontifícia Universidade Católica do Rio de Janeiro. Rio de Janeiro, 2005.

19. MARDER, L. Emprego da técnica de eletrodiálise no tratamento de soluções aquosas contendo cádmio e cianeto. 2002. Dissertação (Mestrado em Ppgem - Programa de Graduação em Engenharia de Materiais) - Universidade Federal do Rio Grande do Sul Coordenação de Aperfeiçoamento de Pessoal de Nível Superior.

20. FATIN-ROUGE N., DUPONT A., VIDONNE A., ET AL., Removal of some divalent cations from water by membrane-filtration assisted with alginate, Water Research, V. 40 pp. 1303-1309, 2006

21. DEL RIO, D. T. Biossorção de cádmio por leveduras Saccharomyces cerevisiae. Dissertação de mestrado da Escola Superior de Agricultura Luiz de Queiroz. Piracicaba, 2004. 